\title{
'NOT AS BAD AS...' THE CONCEPT OF DISADVANTAGE IN THE JUSTIFICATION OF POSITIVE ACTION UNDER UK ANTI-DISCRIMINATION
}

LAW

Victoria Martínez Placencia*

\begin{abstract}
An essential goal of anti-discrimination law is to break the connection between disadvantage and group membership. There should not be a predictable link between being a member of a group with a protected characteristic and being disadvantaged in society. Positive action is the ultimate tool to achieve this aim, however, its application in the UK has been scarce. In this paper, I argue that the relevant concept of disadvantage in discrimination claims is different from the one used to justify positive action. This distinction impacts on the proportionality test and allows clarification of the potentialities and limitations of positive action to redress inequality. This attempt stands from a theoretical point of view but also highlights the reasoning behind recent cases under UK and EU anti-discrimination law.
\end{abstract}

\section{A. INTRODUCTION}

Most liberal democracies endorse the principle of equality as non-discrimination, and many of them have special legislation to identify and sanction discriminatory acts. The right to nondiscrimination is central in the UK legal system, and the Equality Act 2010 (hereinafter 'Equality Act') has a quasi-constitutional status. ${ }^{1}$ However, after decades of antidiscrimination law, the promise of equality is still elusive. The effects of these provisions have been modest and certainly insufficient to address deep inequalities. The formal approach towards equality that has predominated in the interpretation and application of antidiscrimination law is one of the issues to blame for these meagre results. ${ }^{2}$ Following Khaitan's account of anti-discrimination law, in this essay, I highlight disadvantage as an essential concept for anti-discrimination law. ${ }^{3}$ I argue that the purpose of anti-discrimination law is to break the connection between disadvantage and group membership. This approach avoids

\footnotetext{
${ }^{*}$ LL.M. (UCL), Bachelor of Legal and Social Sciences (Universidad Alberto Hurtado). I am grateful to Professor Ronan MacCrea for supervising an earlier version of this article and to the Scholarship Program funded by the Agencia Nacional de Investigación y Desarrollo (ANID), Magíster Becas Chile 2018/73190029. All errors and omissions are my own.

1 Colm O'Cinneide, 'Equality: Current and Future Directions of Travel' (2016) 16 International Journal of Discrimination and the Law 1, 1.

${ }^{2}$ Colm O'Cinneide, 'Positive Action and the Limits of Existing Law' (2006) 13 Maastricht Journal of European and Comparative Law 351, 353; Sandra Fredman, Discrimination Law (2nd edn, OUP 2011) 7-11.

3 Tarunabh Khaitan, A Theory of Discrimination Law (OUP 2015).

(C) 2020, The Authors. This is an open access article distributed under the terms of the Creative Commons Attribution License (CC BY) 4.0 https://creativecommons.org/licenses/by/4.0/, which permits unrestricted use, distribution and reproduction in any medium, provided the original author and source are credited - DOI: https://doi.org/10.14324/111.2052-1871.127.
} 
'Not as Bad as...' The Concept of Disadvantage in the Justification of Positive Action under

\section{UK Anti-Discrimination Law}

excessive attention on different treatment, which ultimately leads to a formal equality interpretation.

One of the most powerful tools to redress inequality is positive action. These measures directly focus on disadvantage to give preferential treatment or special assistance to members of disadvantaged groups. However, the application and evaluation of positive action in the UK have been marginal. ${ }^{4}$ Due to the current regulation of UK and EU law, relevant actors are deterred from engaging with positive action because of the prospect of legal liability. Any different treatment is seen as a suspect discriminatory act, which turns these measures into risky decisions. The justification of positive action through the proportionality test is a heavy burden for public and private actors, one that academia has not thoroughly examined.

The purpose of this essay is to clarify the relevant concept of disadvantage in positive action. The initial question is whether the concept of disadvantage that supports discrimination claims differs from the one underlying positive action and how this definition interacts with the proportionality test. Through this analysis, I hope to provide a better understanding of positive action, facilitating its use, but also acknowledging its limitations. My approach is mainly theoretical, in the sense that I concentrate on abstract conceptualisations. Nevertheless, I focus this analysis on the UK context highlighting recent cases where these concepts have been applied. ${ }^{5}$

In Section B, I analyse the concept of disadvantage as a pillar of anti-discrimination law. I make a normative proposal by defining disadvantage following the capabilities approach, and explaining what the relevant concept of disadvantage is for anti-discrimination law. ${ }^{6}$ Ascribing the UK Equality Act under the anti-discrimination law framework, in Section C describe positive action and its regulation under UK and EU law. In the last Section, I analyse the proportionality principle and I propose a definition of the relevant concept of disadvantage in the justification of positive action.

\section{B. DISADVANTAGE AS A PILLAR OF ANTI-DISCRIMINATION LAW}

\section{A Definition of Disadvantage}

\footnotetext{
${ }^{4}$ Chantal Davies and Muriel Robison, 'Bridging the Gap: An Exploration of the Use and Impact of Positive Action in the United Kingdom' (2016) 16 International Journal of Discrimination and the Law 83.

${ }^{5}$ Last updated: 15 July 2019.

${ }^{6}$ Martha Nussbaum, Women and Human Development: The Capabilities Approach (CUP 2000); Amartya Sen, Inequality Reexamined (OUP 1995).
} 


\section{UCL Journal of Law and Jurisprudence}

Inequalities are still a pressing issue that states and supra state actors are willing to address. For instance, the UN 2030 Agenda for Sustainable Development identifies as essential goals putting an end to poverty and hunger, reducing inequalities and achieving gender equality. ${ }^{7}$ These goals are an acknowledgement that a big proportion of the population is not able to live a free and fulfilling life. Some people exist under unfavourable circumstances and conditions that reduce their chances to live a good life. The concept of disadvantage encompasses these circumstances and conditions.

How we define and measure disadvantage is a key concern when designing a public policy. Disadvantage is a multifactorial phenomenon and any account of it should provide a comprehensive definition. It is not only about economic resources but also about legal structures and inclusion in the community. In this essay, I follow the capabilities approach to define disadvantage, developed by Amartya Sen and especially by Martha Nussbaum. ${ }^{8}$ This account focuses on human capabilities: what people are able to do and to be. ${ }^{9}$ The idea behind this theory is that there are some functions which are central to human life. Capabilities are a reflection of the combination of functions that a person can achieve and from which she or he can decide to achieve. ${ }^{10}$ Only an adequate level of capabilities can assure a life worthy of human dignity. This level includes fundamental entitlements that are independent of the people's preferences and sense of satisfaction. ${ }^{11}$

For Nussbaum, there are ten essential capabilities that encompass the requirements of a life with dignity. A society that cannot guarantee an appropriate threshold level of these capabilities to all its citizens does not have social justice. ${ }^{12}$ Nussbaum synthesises these central human capabilities in a list of ten essential aspects: 1 . Life, 2. Bodily health, 3. Bodily integrity, 4. Senses, imagination and thought, 5. Emotions, 6. Practical reason, 7. Affiliation, 8. Other species, 9. Play, 10. Control over one's environment. ${ }^{13}$ Therefore, disadvantage can be defined as the lack of access to any of these capabilities or its enjoyment below the threshold level required for human dignity. Following this account, disadvantage is a complex notion that depends on the particular circumstances of each person.

\footnotetext{
${ }^{7}$ UN General Assembly, 'Transforming our world: the 2030 Agenda for Sustainable Development' (21 October 2015) UN Doc A/RES/70/1.

${ }^{8}$ Nussbaum (n 6); Sen (n 6).

${ }^{9}$ Nussbaum (n 6) 5.

${ }^{10}$ Amartya Sen, 'Capability and Well Being' in Daniel M Hausman (ed), The Philosophy of Economics: An Anthology (CUP 2008) 271.

${ }_{11}$ Martha Nussbaum, 'Capabilities as Fundamental Entitlements: Sen and Social Justice' (2003) 9 Feminist Economics 33, 34.

12 ibid 40.

13 ibid 41-42.
} 


\section{UK Anti-Discrimination Law}

An aspect of disadvantage that the capabilities approach does not adequately address is the problem of risk. Those who experience more disadvantage are forced to take serious risks to secure some important functions. Therefore, one element of being disadvantaged is to be forced to risk one capability to secure another one. ${ }^{14}$ This vulnerability to risk is involuntary, and entails an unfree decision to prioritise some capabilities over others. For example, a lowskill worker in poverty is more likely to accept a non-meaningful or even exploitative job to secure a livelihood for her and her family.

Despite the individual account of disadvantage encouraged by the capabilities approach, some groups are more likely to suffer disadvantage than others. Most of the time, we can guess who are the most disadvantaged people in society knowing some of their personal characteristics. Individual disadvantage is somehow connected with class or group membership. This phenomenon is common in unequal societies, because 'a society of equals is a society in which disadvantages do not cluster, a society where there is no clear answer to the question of who is the worst off. ${ }^{15}$ Regrettably, in most countries there is always a clear answer to this question. For example, in the UK, black workers with a degree earn $23 \%$ less than white workers. Pakistani or Bangladeshi and black adults are more likely to live in substandard accommodations than White people. ${ }^{16}$ In the UK, like so many other countries, race or ethnicity can be used as predictors of employment and housing conditions.

Anti-discrimination law is one of many tools to address disadvantage. One of the aims of this law is to break the connection between group membership and disadvantage rather than directly tackling disadvantage and their causes. This is the reason why in this essay I refer to 'absolute disadvantage' as the one suffered by individuals disregarding their group membership. While social rights, social benefits, and redistributive measures usually focus on a minimum standard of resources for each individual, anti-discrimination law is a de-clustering tool that deals with group disadvantage. This law operates focusing on protected characteristics rather than wide disadvantages like socioeconomic or geographical disadvantage. This may lead to help one disadvantaged group at the expense of another. ${ }^{17}$ Anti-discrimination law is not enough to overcome deep inequalities and absolute disadvantage, and possibly it is not an appropriate tool either.

\footnotetext{
${ }^{14}$ Jonathan Wolff and Avner De-Shalit, Disadvantage (OUP 2007) 72.

15 ibid 10.

16 Equality and Human Rights Commission (EHRC) 'Race report statistics' 27 December 2018 $<$ https://www.equalityhumanrights.com/en/race-report-statistics $>$ accessed 11 May 2020.

${ }^{17}$ Bob Hepple, Equality: The Legal Framework (2nd edn, Hart Publishing 2011) 173.
} 


\section{The Concept of Disadvantage in Anti-Discrimination law}

In this essay, the starting point is to conceive anti-discrimination law as a particular and distinctive kind of law. At least in a common law context anti-discrimination law share a basic structure and purpose. I follow Khaitan's work in the characterisation of anti-discrimination law, and I identify the Equality Act within this framework. ${ }^{18}$ Under this account, one of the main goals of anti-discrimination law is to break the link between disadvantage and group membership. A difference in treatment is relevant as far as it is disadvantageous. ${ }^{19}$ Therefore, my approach focuses on disadvantage rather than different treatment. I argue that this approach is preferable for three main reasons. First, it avoids essentialising difference which stigmatises some groups as an opposition to the normal group. ${ }^{20}$ Anti-discrimination law is not about classifying people into different groups, but ameliorating disadvantage correlated with group membership. Second, it allows surpassing the limited formal equality understanding of discrimination claims. As the feminist legal theory has long ago criticised, the understanding of discrimination solely as 'different treatment' forces a comparison that imposes a heavy burden on the claimant. ${ }^{21}$ Third, it helps to focus on what this law can truly accomplish for disadvantaged groups. Anti-discrimination law should be understood as one, among other tools, to achieve equality. They do not fit every egalitarian purpose and their scope is limited to the disadvantages that are connected with group membership. Inequality and absolute disadvantage also exist disconnected from a protected characteristic; for instance, poverty and socio-economic disadvantages.

The focus on disadvantage may seem unusual and counter-intuitive for antidiscrimination law. However, I argue in this essay that it is the concept of disadvantage that determines the structure and the purpose of this law. On a practical level, even the Equality Act defines direct discrimination as treating someone less favourably than another person who does not share the protected characteristic. ${ }^{22}$ The problem is not the different treatment but the less favourable one. Different treatment is relevant because it is a clue that there may be a

\footnotetext{
${ }^{18}$ Khaitan (n 3).

${ }^{19}$ Kasper Lippert-Rasmussen, Born Free and Equal? A Philosophical Inquiry into the Nature of Discrimination (OUP 2014) 15.

${ }^{20}$ Iris Marion Young, Justice and the Politics of Difference (Paperback reissue, Princeton University Press 2011) 151.

${ }^{21}$ Rosemary C Hunter (ed), Rethinking Equality Projects in Law: Feminist Challenges (Hart Pub 2008) 87.

${ }^{22}$ Equality Act 2010, s 13.
} 
'Not as Bad as...' The Concept of Disadvantage in the Justification of Positive Action under

\section{UK Anti-Discrimination Law}

discriminatory practice. However, only disparate treatment connected with a presumption that this is founded on a protected characteristic constitutes discrimination. ${ }^{23}$

Equality as a legal and political goal cannot be reduced to anti-discrimination law or totally addressed by it. The legal discourse is important to overcome inequality, but the law should not necessarily be the centre of every effort. ${ }^{24}$ Nevertheless, this discourse is relevant because the law itself is part of the structures that have maintained the subjugation of disadvantaged groups. ${ }^{25}$ Anti-discrimination law's aim is humble; to allow some members of underprivileged groups to access goods and opportunities in specific contexts. This aim relates to equality but also to other important values such as liberty and dignity. What is important is to acknowledge that disadvantage is the key element of anti-discrimination law. Different treatment, lack of access or even restrictions to goods and opportunities matter as long as they are connected with disadvantage.

It could be argued that discrimination is wrong and unlawful even when it does not prevent us from achieving capabilities. ${ }^{26}$ Under this understanding, any disparate treatment triggers the protection of anti-discrimination law. From my perspective, this law is designed to deal with severe disadvantage that affects essential spheres of life. Different treatment which does not affect basic capabilities or different treatment suffered by advantageous groups in order to give preference to members of a disadvantaged group, do not deserve the same protection of the law. These acts may constitute a different treatment, but they should not be unlawful under the principle of equality as non-discrimination. Equality as non-discrimination forces us to acknowledge that some groups are disadvantaged and other groups are advantaged. It entails that the problem of discrimination is that some groups are subjugated because they face a second-class status. ${ }^{27}$

The concept of disadvantage plays an important role in the architecture of antidiscrimination law. The protected characteristics (or grounds), the way in which discrimination is claimed and proved, all these aspects are influenced by a specific notion of disadvantage. In this essay, I argue that there is a particularly relevant kind of disadvantage for anti-

\footnotetext{
${ }^{23}$ European Union (ed), Handbook on European Non-Discrimination Law (2018 edn, Publications Office of the European Union 2018) 231.

${ }^{24}$ Carol Smart, Feminism and the Power of Law (Routledge 1989) 163-5.

${ }^{25}$ Owen Fiss, 'The Accumulation of Disadvantages' (2018) 106 California Law Review 1945, 1946.

${ }^{26}$ Linda Barclay, 'The Importance of Equal Respect: What the Capabilities Approach Can and Should Learn from Human Rights Law' (2016) 64 Political Studies 385, 394.

${ }^{27}$ Cass Sunstein, 'The Anticaste Principle' (1994) 92 Michigan Law Review 2410, 2431.
} 
discrimination law. It must be a serious group disadvantage that can be measured in relation to an advantaged group within each ground or category.

a) Serious Disadvantage

The inclusion of every ground of discrimination is a response to serious disadvantages with historical roots and political consequences. According to Khaitan, the kind of disadvantage required is abiding, pervasive and substantial. ${ }^{28}$ It is abiding because it exists over a certain length of time. It is pervasive because it spreads into several aspects of a person's life. It is substantive because it seriously affects her; it means more than an inconvenience. ${ }^{29}$ There are usual signs of serious disadvantage such as marginalization from the political process, ${ }^{30}$ and small or disproportionate participation in some areas of life. ${ }^{31}$

Following the capabilities approach, a serious disadvantage prevents people from developing basic human functions at an adequate level compatible with human dignity. From Nussbaum's account, an underdevelopment of any of the ten basic human capabilities means a disadvantage. This holistic approach includes several factors from being able to have good health and shelter to being able to love, care and grieve for others. ${ }^{32}$ This complex definition explains the experience of systemic disadvantage suffered by some groups. It is systemic because it operates in relevant spheres of life and relates to the basic participation of citizens in a democracy. ${ }^{33}$ Only serious disadvantage like this triggers the protection of antidiscrimination law and explains why some categories are included and others are not. This is also the reason why some anti-discrimination laws apply only to some relevant contexts such as employment, education, and health care, among others.

\section{b) Group disadvantage}

Another feature of the concept of disadvantage in anti-discrimination law is that what is relevant is not individual disadvantage but group disadvantage. It is the disadvantage suffered by a group which drives the recognition of a discrimination ground. These grounds acknowledge that disadvantage is disproportionately concentrated among members of some groups. ${ }^{34}$ In this sense, anti-discrimination law is tailored to answer to the disadvantaged

\footnotetext{
${ }^{28}$ Khaitan (n 3).

29 ibid 36.

${ }^{30}$ Fredman (2) 134.

31 Evadne Grant, 'Disadvantage and Discrimination: The Emerging Jurisprudence of the South African Constitutional Court' 51 Northern Ireland Legal Quarterly 174, 174.

${ }^{32}$ Nussbaum, Women and Human Development: The Capabilities Approach (n 6) 78.

${ }^{33}$ Sunstein (n 27) 2429.

${ }^{34}$ Fredman (n 2) 26.
} 


\section{UK Anti-Discrimination Law}

groups that exist in a given society. ${ }^{35}$ The inclusion of discrimination grounds depends on the evolution of both legal and social factors. ${ }^{36}$ What underlies those factors is the disadvantage suffered by a group which is urgent to address.

Group membership is relevant because of its correlation with disadvantage. It is not relevant as an identity element. Disadvantaged groups may or may not share a common identity or affinity, but this characteristic is not important in terms of discrimination. ${ }^{37}$ The focus of anti-discrimination law is disadvantage rather than difference. The individual is protected as long as it is a member of a protected group and not because of its individual (absolute) disadvantage.

\section{c) Relative disadvantage}

One of the essential aims of anti-discrimination law is to close the advantage gap between groups. Discrimination grounds classify persons into groups with a significant advantage gap between them. ${ }^{38}$ What is relevant is the disadvantage of one group in relation to the other group under the same category. Members of the protected group are more likely to suffer disadvantage than the members of the cognate advantaged group. ${ }^{39}$ For example, regarding the protected characteristic of race, Pakistani people are more likely to suffer disadvantage than White people in the UK.

Grounds of discrimination are relevant because they showcase an advantage gap between groups. I think this is a necessary element to understand how anti-discrimination law works and how a characteristic becomes protected. For Sunstein, the key aspect of protected characteristics is that they are morally irrelevant. ${ }^{40} \mathrm{He}$ argues that without reasonable justification, legal and social structures should not turn morally irrelevant differences, such as race or ethnicity, into systematic social disadvantages. ${ }^{41} \mathrm{I}$ disagree with this argument because I do not think that the moral justification of the categories is a necessary element of the definition and application of anti-discrimination law. It is not designed to deal with the injustice of the advantaged distribution but to reduce the advantage gap, at least in some cases. Not all morally irrelevant characteristics deserve the concern of the law (i.e. eye or hair colour); they are important because there is a significant advantage gap between groups (i.e. race or gender).

\footnotetext{
35 ibid 38.

36 ibid.

37 Young (n 20) 152.

${ }^{38}$ Khaitan (n 3) 51.

39 ibid.

${ }^{40}$ Sunstein (n 27) 2431.

41 ibid 2429.
} 


\section{UCL Journal of Law and Jurisprudence}

In fact, in positive action, the same characteristics are the justification of preferential treatment to overcome disadvantage.

In summary, the concept of disadvantage in anti-discrimination law is essential to understand the structure of this law and how it works. I argue that this concept is specific; it is serious, relative, and centred on group disadvantage. Despite the importance of this particular kind of disadvantage, it is not necessary to prove it in discrimination claims. The inclusion of grounds or protected characteristics prevents claimants from proving in individual cases that the less favourable treatment they suffer is the cause of disadvantage. Generally, claimants do not need to prove individual disadvantage in relation to a comparator. ${ }^{42}$ In direct discrimination claims, proving a different treatment is usually enough to proceed. Indirect discrimination claims are more dependent on the concept of disadvantage because it is necessary to prove a disparate impact that unjustifiably affects persons who share a protected characteristic. However, in positive action the concept of disadvantage is crucial for its justification and it may require special evidence.

\section{POSITIVE ACTION}

Measures that enable members of disadvantaged groups to increase their participation in relevant aspects of life, such as employment and higher education, are an essential part of antidiscrimination law. Favouring members of disadvantaged groups is a logical step to overcome relative group disadvantage. The way these measures are conceptualised depends on the jurisdiction. For example, in the US, the term affirmative action is used while in the EU, it is more common to use the term positive action. However, the term we use for these measures also has a substantial connotation. For instance, using the alternatives of positive discrimination, reverse discrimination, or preferential treatment denotes a more powerful intervention or even a pejorative meaning. On the other hand, using the term of positive action implies a softer or weaker sort of measure. ${ }^{43}$ In this essay, I use the term positive action following the common understanding in the UK. ${ }^{44}$

Unlike discrimination claims, positive action goes beyond the individual case and places the focus on the disadvantaged group. The initiative is not from the claimant but from

\footnotetext{
${ }^{42}$ Khaitan (n 3) 35.

${ }^{43}$ Aileen McHarg and Donald Nicolson, 'Justifying Affirmative Action: Perception and Reality' (2006) 33 Journal of Law and Society $1,2$.

${ }^{44}$ McCrudden, Christopher, 'A Comparative Taxonomy of "Positive Action" and "Affirmative Action" Policies' (2012) 12-04 Queen's University Belfast Law Research Paper, 1, 1. <https://ssrn.com/abstract=2089374> Accessed 11 May 2020.
} 


\section{UK Anti-Discrimination Law}

the best-placed actors to address disadvantage and inequality. ${ }^{45}$ However, the concept and the debate around the application of positive action are politically charged. Efforts to overcome disadvantage of unpopular minorities, especially by reducing opportunities for the advantaged majority, usually face opposition. ${ }^{46}$

There are several theoretical foundations for positive action. For McCrudden there are three main kinds of arguments to justify preferential treatment: compensation, distributive justice and social utility. ${ }^{47}$ The first set of arguments focuses on the remedial effect of positive action as a way to compensate for the pernicious effect of past discrimination. For instance, in the US, the earlier justification for affirmative action was conceived as reparations for the suffering caused by slavery and segregation. ${ }^{48}$ The problem with this kind of justification is that those who usually benefit from these measures are the most privileged within the disadvantaged group. At the same time, those who are required to lose opportunities for members of such groups are not responsible for past discrimination. ${ }^{49}$ The second set emphasises the public interest in increasing opportunities for the worst-off. An apparent inequality is permitted as long as it benefits the least advantaged. ${ }^{50}$ The distributive justice approach focuses on substantial meanings of equality rather than an equal treatment rule. The third set justifies positive action because diversity is a valuable and desirable element in every sphere of life. ${ }^{51}$ Preferential treatment is given to members of disadvantaged groups because of what they can offer, not because they need special assistance. ${ }^{52}$

The concept of positive action entails a wide variety of measures, including remedial and non-remedial ones. Remedial measures benefit persons who have suffered disadvantage due to past discrimination. ${ }^{53}$ For example, when a person is liable for discriminatory acts and is forced to take actions as a form of reparation. Non-remedial measures are not the consequence of wrongful acts. According to Khaitan, non-remedial measures can be classified

\footnotetext{
45 ibid 5.

${ }^{46}$ Lisa Waddington and Mark Bell, 'Exploring the Boundaries of Positive Action under EU Law: A Search for Conceptual Clarity’ (2011) 48 Common Market Law Review 1503, 1508.

${ }^{47}$ Christopher McCrudden, 'Rethinking Positive Action’ (1986) 15 Industrial Law Journal 219, 237.

${ }^{48} \mathrm{McHarg}$ and Nicolson (n 43) 9.

49 ibid 10.

${ }^{50}$ McCrudden, 'Rethinking Positive Action' (n 47) 238.

51 ibid 239.

${ }^{52}$ McHarg and Nicolson (n 43) 16.

${ }^{53}$ Khaitan (n 3) 81.
} 


\section{UCL Journal of Law and Jurisprudence}

into three sets depending on the tools they employ, their sensitivity to protected characteristics and whether they are voluntary, mandatory or contractual. ${ }^{54}$

Depending on the tools, there can be facilitative or distributive measures. While facilitative measures include duties of disclosure of information, distributive measures seek to influence the behaviour of controllers of resources or opportunities such as employers or universities. This includes preferential treatment, quotas and tie-break rules, among others. Regarding the way in which these actions engage with protected characteristics, they can be direct or indirect measures. Direct ones target persons who share a protected characteristic, like quotas for a specific minority. Indirect measures are designed to have a beneficial impact on protected groups, but they do not target the protected characteristic. For example, if the goal is to favour members of ethnic minorities in higher education, there can be preferential treatment for students whose parents do not hold a degree. This action will likely benefit them without targeting them directly. These non-remedial measures can also be voluntary, contractual or mandatory. Contractual measures are clauses usually imposed by public sector procurement contracts. Voluntary measures allow private persons to undertake positive action, and this usually takes the form of an exemption from direct discrimination liability. ${ }^{55}$ Mandatory measures impose specific duties to some actors, such as those implemented in Northern Ireland to secure fair participation in employment to Protestant and Roman Catholic workers. ${ }^{56}$

For O'Cinneide, the term positive action includes 'any form of proactive action designed to benefit a disadvantaged group. ${ }^{57}$ In this sense, mainstreaming initiatives, special welfare assistance and any kind of preferential treatment are positive actions. In the employment context, McCrudden identifies five types of actions. ${ }^{58}$ First, measures to eradicate discrimination by replacing discriminatory practices. Second, inclusionary policies to increase the proportion of members of disadvantaged or underrepresented groups. Third, outreach programmes designed to attract members of such groups. Fourth, preferential treatment to reduce underrepresentation by directly favouring members of disadvantaged groups. Fifth, redefining merit through a redefinition of qualifications for a job.

A wide understanding of positive action blurs the distinction between them and other types of measures like reasonable accommodations and positive duties. Reasonable

\footnotetext{
54 ibid 81-86.

55 ibid 85.

${ }^{56}$ Fair Employment and Treatment (Norther Ireland) Order 1998 arts 55, 56, 72.

57 O'Cinneide, 'Positive Action and the Limits of Existing Law' (2) 354.

${ }^{58}$ McCrudden, 'Rethinking Positive Action' (n 47) 223-225.
} 


\section{UK Anti-Discrimination Law}

accommodations operate in the protected characteristic of disability and focus on individual requirements rather than group disadvantage. ${ }^{59}$ They are usually mandatory because a lack of adjustments puts a person with disabilities in substantial disadvantage, which itself constitutes discrimination. Under the Equality Act, there is a specific duty to make reasonable adjustments. ${ }^{60}$ Reasonable accommodations are also less controversial and easily accepted by people who do not have disabilities. All the same, positive duties like data collection and mainstreaming aim to promote equality into decision-making and service delivery. ${ }^{61}$ For example, this is the role of the public sector equality duty in the UK context. ${ }^{62}$ Other public policies targeting disadvantaged groups are not necessarily positive action or even included under the framework of anti-discrimination law. Social welfare tackles disadvantage and inequality but they do not do so dealing with group or relative disadvantage. Equality and social inclusion are valid political goals that can be pursued by non-legal tools.

These distinctions are important because anti-discrimination law in general, and positive action in particular, entail procedural requirements and judicial scrutiny. An overinclusive concept of positive action has the risk of hampering legitimate public policy. In this sense, positive actions are measures targeted at a particularly disadvantaged group addressing disadvantage in a specific context such as employment or education. ${ }^{63}$ Following the focus of this essay, the purpose of positive action is to reduce the advantage gap between groups by promoting the access of members of a disadvantaged group into valuable opportunities, goods or services. These actions may take diverse forms, and any definition should not limit the possibilities. Contemporary or future organisations may design new and creative measures to redress disadvantage. ${ }^{64}$

\section{Positive Action in the UK: Equality Act and EU Law}

The Equality Act 2010 is a comprehensive legislation where discrimination is an important but not exclusive part. ${ }^{65}$ It replaced nine pieces of legislation about protected characteristics such as race, gender and age. It also sought to implement the EU directives on the matter. The Race Relations Act 1968 and the Sex Discrimination Act 1975 introduced positive action provisions

\footnotetext{
${ }^{59}$ Waddington and Bell (n 46) 1518.

${ }^{60}$ Equality Act 2010, s 20.

${ }^{61}$ Waddington and Bell (n 46) 1521.

${ }^{62}$ Equality Act 2010, pt 11, ss 149-157.

${ }^{63}$ Waddington and Bell (n 46) 1523.

${ }^{64}$ Lizzie Barmes, 'Equality Law and Experimentation: The Positive Action Challenge' (2009) 68 Cambridge Law Journal 623, 624.

${ }^{65}$ Hepple (n 17) 2.
} 
in the UK. These provisions were seldom used and outdated in comparison with EU directives. ${ }^{66}$ Nowadays, the Equality Act includes two provisions specifically regulating positive action, ${ }^{67}$ and other sections allowing positive action in the activities of charitable organisations. ${ }^{68}$ These sections establish a permissive regulation rather than a mandatory one; positive action is not prohibited when it complies with the legal requirements. This shows how under UK law any different treatment is under suspicion of being discriminatory, even when it favours a disadvantaged group.

Section 158 includes a general positive action applicable to all protected characteristics under the Equality Act. Section 159 establishes special measures for recruitment and promotion in employment or equivalent contexts. A general positive action can have the aims of (a) overcoming or minimising disadvantage, (b) meeting especial needs, or (c) increasing the participation of persons who share a protected characteristic. ${ }^{69}$ To achieve one or more of these aims, a person or organisation is allowed to take any proportionate action. According to the Explanatory Notes, the extent to which a positive action is proportionate depends, among other things, on 'the seriousness of the relevant disadvantage, the extremity of need or underrepresentation and the availability of other means of countering them. ${ }^{70}$ Section 159 allows persons or organisations to treat someone more favourably in connection with recruitment and promotion than another person on the basis of having a protected characteristic. ${ }^{71}$ This action must be proportionate to the aim of (a) overcoming or minimising disadvantage, or (b) increasing the participation of persons who share a protected characteristic. ${ }^{72}$ This type of positive action only applies under three conditions: (a) the person who shares the protected characteristic is as qualified as the person who does not share it, (b) the person or organisation taking the action does not have a policy of preferential treatment favouring persons with the protected characteristic, and (c) the action is a proportionate means to achieve the aim. According to the Explanatory Notes, the regulation of positive action in the employment context does not allow employers to have a policy of automatically favouring people who share

\footnotetext{
66 ibid 157.

${ }^{67}$ Equality Act 2010, ss 158 and 159.

${ }^{68}$ Equality Act 2010, ss 193 and 194.

${ }^{69}$ Equality Act 2010, s 158 (1) and (2).

${ }^{70}$ Explanatory Notes to the Equality Act 2010, para 512.

${ }^{71}$ Equality Act 2010, s 159 (3).

${ }^{72}$ Equality Act 2010, s 159 (1) and (2).
} 


\section{UK Anti-Discrimination Law}

a protected characteristic; in fact, there is a prohibition to do so. ${ }^{73}$ Each case must be considered on its merits, within the limitations of EU law. ${ }^{74}$

These provisions require a complex proportionality test which includes vague concepts such as disadvantage and merit. There is little evidence of the use of positive action in the UK and a lack of empirical and evaluative research. ${ }^{75}$ However, it is not uncommon for employers to use positive action permitted by section 158 . These are usually outreach measures to increase the participation of some disadvantaged groups like black, Asian and other minority employees. $^{76}$ Likewise, there are some examples of positive action in relation to apprenticeships, especially to increase ethnic minorities and women representation. ${ }^{77}$ The positive action permitted under section 159 is less applied; employers are reluctant to use it because they fear the possibility of legal drawbacks. ${ }^{78}$ Small scale empirical research shows that public sector employers are more aware of the existence and scope of positive action than their private counterparts. ${ }^{79}$ These public actors are engaged with equality measures due to the public sector equality duty established by the Equality Act. ${ }^{80}$

The low use of positive action in the UK and the fear to engage with more intense measures shows a chilling effect encouraged by the lack of clarity of the provisions and the growing concern about legal liability. The complexities of the proportionality test and the vagueness of the concepts of disadvantage and merit make these regulations difficult to grasp by private organisations. Moreover, the constant focus on different treatment as the essential element of anti-discrimination law prevents actors from considering preferential treatment as a means to redress disadvantage. This idea is reinforced by EU law and the Court of Justice of the European Union (ECJ) case law about positive action.

The European Charter states that everyone is equal before the law and prohibits any discrimination on the grounds of nationality, sex, race, language, among others. ${ }^{81}$ However, the principle of non-discrimination can only be applied within the scope of EU law. Several Directives constitute the European anti-discrimination law which has different levels of

\footnotetext{
${ }^{73}$ Explanatory Notes to the Equality Act 2010 para 518.

${ }^{74}$ Explanatory Notes to the Equality Act 2010 para 520.

${ }^{75}$ Chantal Davies, 'Exploring Positive Action as a Tool to Address Under-Representation in Apprenticeships' (2019) Equality and Human Rights Commission 35.

${ }^{76}$ Davies and Robison (n 4) 92.

${ }^{77}$ Davies (n 75) 36.

${ }^{78}$ Davies and Robison (n 4) 96.

79 ibid 95.

${ }^{80}$ Equality Act 2010, ss 149-157.

${ }^{81}$ Charter of Fundamental Rights of the European Union, arts 20 and 21.
} 
protection depending on the grounds. ${ }^{82}$ The protected characteristics of race and ethnicity have the widest protection covering access to employment, welfare systems, and goods and services. Sex discrimination is prohibited in the context of access to employment, social security (narrower than welfare system), and goods and services. The grounds of sexual orientation, disability, religion or belief are protected only in the access to employment. ${ }^{83} \mathrm{EU}$ antidiscrimination law allows positive action in every Directive. For example, regarding race discrimination, it is established that 'the principle of equal treatment shall not prevent any Member State from maintaining or adopting specific measures to prevent or compensate for disadvantages linked to racial or ethnic origin. ${ }^{84}$

The ECJ has only reviewed positive action in the context of gender equality. ${ }^{85}$ In these cases, male applicants made discrimination claims against preferential treatment towards female candidates in the employment context. From the case law, the Court has set the standards to assess whether a positive action is proportionate and therefore lawful. In Kalanke, the ECJ held that guaranteeing women 'absolute and unconditional priority for appointment and promotion go beyond promoting equal opportunities' ${ }^{86}$ For the Court, positive action is permissible as long as it enhances equality of opportunities; equality of results by granting preferential treatment is out of limits. ${ }^{87}$ In Marschall, the Court stated that any preferential treatment should guarantee that candidatures are subjected to an objective assessment which considers all pertinent criteria. In this sense, if a male candidate possesses an essential characteristic or qualification, it can tilt the balance and override the priority to female candidates. ${ }^{88}$ In Briheche, the Court held as disproportionate a provision that automatically and unconditionally gives priority to women excepting them from the age limit to access public sector employment. Nevertheless, the Court reiterated that Member States can prevent or

\footnotetext{
${ }^{82}$ Council Directive 2000/43/EC of 29 June 2000 implementing the principle of equal treatment between persons irrespective of racial or ethnic origin OJ L180/22; Council Directive 2000/78/EC of 27 November 2000 establishing a general framework for equal treatment in employment and occupation OJ L303/16; Directive 2006/54/EC of the European Parliament and of the Council of 5 July 2006 on the implementation of the principle of equal opportunities and equal treatment of men and women in matters of employment and occupation (recast) OJ L204/23; Council Directive 2004/113/EC of 13 December 2004 implementing the principle of equal treatment between men and women in the access to and supply of goods and services OJ L373/37.

${ }^{83}$ European Union (n 23) 34.

${ }^{84}$ Council Directive 2000/43/EC of 29 June 2000 implementing the principle of equal treatment between persons irrespective of racial or ethnic origin OJ L180/22, art 5.

${ }^{85}$ European Union (n 23) 74.

${ }^{86}$ Case C-450/93 Kalanke v Bremen [1995] ECR I-3051 para 22.

87 Takis Tridimas, The General Principles of EU Law (2nd edn, OUP 2006) 112.

${ }^{88}$ Case C-409/95 Marschall v Land Nordrhein-Westfalen [1997] ECR I-6363, para 33.
} 
'Not as Bad as...' The Concept of Disadvantage in the Justification of Positive Action under

\section{UK Anti-Discrimination Law}

compensate for disadvantages in professional careers to ensure full equality in practice between men and women. ${ }^{89}$

In Badeck, it was accepted that some neutral criteria to assess candidates might favour women as long as they are capable of benefitting men as well. However, the Court rejected the possibility that fix quotas for women could be compatible with EU law. This was considered a measure that substitutes equality of opportunities for equality of results..$^{90}$ In the Abrahamsson case, a measure that prioritises women when the merits gap between candidates of each sex was not significant was considered incompatible with EU law. This was regarded as an automatic preference based on the mere fact of belonging to the underrepresented sex. ${ }^{91}$

In a different context, in Lommers, the Court examined the claim of a male employee challenging the preferential treatment for women in the allocation of a nursery service available for public sector staff. The Court acknowledged that equality of opportunities for working mothers could be achieved including working fathers because this will also help to break traditional division of roles between men and women. ${ }^{92}$ However, due to resource scarcity women should have preference because they are more likely to interrupt their careers to take care of children. ${ }^{93}$ In Pedro Roca Álvarez the Court held that granting a right only for employed mothers to take a leave in the first nine months following the birth of a child is discriminatory when the same right is not granted for fathers in the same status when the mother is not an employed person. ${ }^{94}$ The reasoning behind this ruling was that the right was an advantage for working mothers, but this effect is reinforced if the father is also entitled to take this leave in the place of the mother. ${ }^{95}$

The ECJ case-law transitioned from a strong formal equality approach in Kalenke towards a more substantial view of equality in later cases. However, any form of substantive positive action that gives automatic preference to women will probably not survive under the current view of the Court. ${ }^{96}$ The real burden of applying positive action in practice is avoiding legal liability for direct discrimination, and this means an effort to find a justification capable of surpassing a proportionality test. The UK regulation on positive action was designed to

\footnotetext{
${ }^{89}$ Case C-319/03 Briheche v Ministre de l'Interieur [2004] ECR I-8807. para 30.

${ }^{90}$ Case C-158/97 Badeck's application [2000] ECR I-1875, para 47.

${ }^{91}$ Case C-407/98 Abrahamsson v Fogelqvist [2000] ECR I-5539, paras 52-53.

92 Case C-476/99 Lommers v Minister van Landbouw [2002] ECR I-2891, para 41.

93 ibid para 47.

${ }^{94}$ Case C-104/09 Pedro Roca Álvarez v Sesa Start España ETT SA [2010] ECR I-8661 para 39.

95 ibid para 35.

96 O'Cinneide, 'Positive Action and the Limits of Existing Law' (n 2) 357.
} 
strengthen its position in an eventual challenge before the ECJ. ${ }^{97}$ Therefore, lighter forms of positive action are encouraged and those that can conflict with European standards like section 159, are strictly controlled. Nevertheless, the influence of EU law in the advancement of UK anti-discrimination law is remarkable, especially on equal pay and pregnant workers' rights. ${ }^{98}$ EU law regulation and limitations on this matter are still uncertain and there is a wide range of positive action permitted and used by several Member States. ${ }^{99}$

UK and EU anti-discrimination law are intricately linked; therefore, Brexit will also have effects on this area. While the Equality Act and its Northern Ireland equivalent will continue without changes, it is the interpretation of these provisions that will mainly be affected. ${ }^{100}$ UK courts will be no longer bound to follow ECJ case law and EU Directives; thus their interpretation may differ in the future. It is unlikely that there will be a fast shift of perspectives; the principle of equality as it is understood by EU law has been embraced by UK policy-makers, judiciary and society. ${ }^{101}$ Nevertheless, it is an opportunity to shape a new body of jurisprudence that departs even more from the formal equality understanding of antidiscrimination law. It is also a chance to develop a flexible and deferential proportionality test for positive action, one that truly encourages its use. The degree to which these opportunities improve the current situation will depend on the work of national bodies such as the Equality and Human Rights Commission (EHRC) and the work of lawyers through litigation.

\section{DISADVANTAGE IN THE JUSTIFICATION OF POSITIVE ACTION}

The initial question of this essay is whether the concept of disadvantage that I attempted to define in Section B is applicable to positive action. This question is relevant because as I have shown the aim and the justification of positive action is deeply intertwined with our understanding of disadvantage. In the first section, I stated that the relevant disadvantage for anti-discrimination law meets three qualities; it is a serious, relative, group disadvantage. These conditions qualify the definition of disadvantage, a concept which I have argued is better understood following the capabilities approach. Under this theory, disadvantage is a concept that encompasses the lack of access or underdevelopment of basic human capabilities, below a human dignity threshold.

\footnotetext{
${ }^{97}$ Barmes (n 64) 645.

${ }^{98}$ Catriona Cannon, 'Brexit and Discrimination Law' (2019) 150 Employment Law Bulletin 2.

${ }^{99}$ Davies and Robison (n 4) 88.

100 Cannon (98) 3.

101 ibid.
} 
'Not as Bad as...' The Concept of Disadvantage in the Justification of Positive Action under

\section{UK Anti-Discrimination Law}

The Equality Act does not define disadvantage. The EHRC states that it may include 'exclusion, rejection, lack of opportunity, lack of choice, or barriers to accessing services.' 102 In their view, disadvantage may be obvious from national statistical data or may require qualitative evidence. ${ }^{103}$ In the employment context, such disadvantage may be related to legal, social or economic barriers "which make it difficult for people of a particular protected group to enter into or make progress in an occupation, a trade, a sector or workplace.' ${ }^{104}$ These explanations support the idea that disadvantage is not one-dimensional, and it varies depending on the context because it may affect different capabilities.

I argued that anti-discrimination laws such as the Equality Act are de-clustering tools that aim to break the link between disadvantage and group membership. In doing this task, positive action is the ultimate instrument. Instead of working on a case-by-case basis, these measures have the potential of reaching several disadvantaged persons by giving them a preferential treatment, or at least a special assistance. My claim in this Section is that as a consequence of the justification standard required by the Equality Act and EU law, the concept of disadvantage in positive action differs from the one used in discrimination claims. This argument relies on the way in which proportionality works and their relationship with the concepts of merit and disadvantage.

\section{Justification of Positive Action: The Proportionality Principle}

The provisions that regulate positive action in the UK allow these measures to pursue three different aims: to overcome or minimise disadvantage, to meet different needs, or to increase the participation of a group when it is disproportionately low. One of these aims is sufficient to trigger positive action, but an actor or organisation may also try to achieve all of them. The beneficiaries must be persons who share a protected characteristic, and it is also possible that they meet all of the three conditions. For instance, persons from an ethnic minority can suffer economic disadvantage correlated with their group membership and also be underrepresented in a particular field.

To be lawful, the undertaken positive action must be a proportionate means to achieve one or more of the described aims. For the EHRC, this particular proportionality test is the 'balancing of competing relevant factors.' 105 These factors depend on the aim pursued, and it

\footnotetext{
102 Equality and Human Rights Commission, Services, Public Functions and Associations: Statutory Code of Practice (TSO 2011), 138.

103 ibid.

${ }^{104}$ Equality and Human Rights Commission, Employment: Statutory Code of Practice (TSO 2011), 163.

105 ibid 168 .
} 
includes the goal and costs of the action taken, 'the seriousness of the relevant disadvantage, the degree to which the need is different and the extent of the low participation in the particular activity will need to be balanced against the impact of the action on other protected groups, and the relative disadvantage, need or participation of these groups.' 106

Following Alexy, the proportionality test consists of three sub-principles: suitability, necessity and proportionality in the narrower sense. The idea of optimisation underpins all three of these principles. ${ }^{107}$ The suitability test assesses the relationship between means and ends. The examined measure should be suitable to achieve the chosen aim. The necessity test implies that the measure is the least restrictive alternative to achieve the chosen aim. The third test considers proportionality strictly, in a sense that the measure is disproportionate if it imposes an excessive burden to an individual, even if it is suitable and necessary. ${ }^{108}$ The suitability and necessity tests refer to factual possibilities of optimisation, where the question is if one position can be improved without detriment to the other. These sub-principles are concerned with avoiding all avoidable costs. ${ }^{109}$ There is a conflict of principles or interests when some costs are unavoidable. Therefore, the third principle is a balancing exercise where the relevant factors are weighed against each other. In this last test, what is important is the relationship between the benefit gained by the measure and the limitations on rights imposed by it. ${ }^{110}$

The principle of proportionality is a general principle of EU law, moreover, it is one of the principles that guide the actions, content, and form of the European Union. ${ }^{111}$ This principle transcends jurisdictions and it is part of several legal orders. ${ }^{12}$ The ECJ applies it to assess the adverse consequences on legally protected interests, and determines 'whether those consequences are justified in view of the importance of the objective pursued. ${ }^{113}$ The Court applies the three-step test assessing the suitability, necessity and proportionality of measures. However, the content and intensity of the test are not fixed. For instance, the ECJ uses different interpretations of the proportionality test depending on the rights and interests at stake. ${ }^{114}$ When

\footnotetext{
${ }^{106}$ Equality and Human Rights Commission, Services, Public Functions and Associations: Statutory Code of Practice (n 102) 142.

${ }^{107}$ Robert Alexy, 'Proportionality, Constitutional Law, and Sub-Constitutional Law: A Reply to Aharon Barak' (2018) 16 International Journal of Constitutional Law 871, 873.

108 Tor-Inge Harbo, 'The Function of the Proportionality Principle in EU Law' (2010) 16 European Law Journal 158, 165.

109 Alexy (n 107) 873.

${ }^{110}$ Aharon Barak, 'Proportionality and Principled Balancing' (2010) 4 Law \& Ethics of Human Rights 1, 7.

${ }^{111}$ Consolidated Version of the Treaty on European Union [2008] OJ C115/13, art 5.

112 Harbo (n 108) 159.

113 Tridimas (n 87) 139.

114 Harbo (n 108) 173-185.
} 


\section{UK Anti-Discrimination Law}

the Court assesses the proportionality of measures that affects individual rights, they use a strict version. The proportionate measure is the least restrictive alternative. On the other hand, when the ECJ examines Community measures, it uses an interpretation closer to a reasonableness test. Likewise, UK courts and tribunals depart from a strict interpretation of the necessity test examining the justification of indirect discrimination. They prefer to apply a reasonable necessity test which is detrimental to claimants. ${ }^{115}$

The proportionality test to determine the lawfulness of positive action entails the same three-step assessment. In this case, we face a conflict of interests rather than a conflict of rights or principles. The potential beneficiaries and persons affected by these measures do not have any rights concerning the application of positive action. First of all, because these are voluntary measures and not mandatory ones. At least under the Equality Act, positive action is nonremedial and persons who carry them out do not have a duty to do so. The rights underpinning this analysis are the same for both parties; equality and the prohibition of discrimination. Positive action is an essential measure to overcome relative disadvantage and therefore a way to achieve substantial equality. At the same time, a preferential treatment may impact on other groups or produce 'collateral discrimination.' 116 The acknowledgement of this context does not mean that the justification of positive action demands a balance of rights.

The first step of the proportionality test requires that the action should be reasonably suitable to achieve the pursued aim. As we have seen, positive action can take an enormous variety of forms and it offers a wide scope for innovation. What is essential is to have clarity about which are the aims trying to be achieved (tackle disadvantage, special needs or disproportionate participation), and which is the targeted group. For example, a company in the engineering sector has data that in the UK women experience disadvantage in pursuing a career in engineering. The low participation of women and the positions they fulfil in the company showcase the same handicap. In order to tackle this particular disadvantage and the disproportionate participation of women in the profession, the company decides to offer career fairs, especially for girls and women. ${ }^{117}$ In this case, the measure (offering career fairs for women) is suitable to achieve the aim (increase participation and overcome disadvantage of women in the engineering career).

\footnotetext{
115 Jackie A Lane and Rachel Ingleby, 'Indirect Discrimination, Justification and Proportionality: Are UK Claimants at a Disadvantage?’ (2018) 47 Industrial Law Journal 531.

${ }^{116}$ Khaitan (n 3) 145.

${ }^{117}$ This example is based on the one presented in Equality and Human Rights Commission, Employment: Statutory Code of Practice (n 104) 164.
} 


\section{UCL Journal of Law and Jurisprudence}

The second step is necessity. In my view, this standard of evaluation should be more deferential to the actor undertaking positive action. There are a number of reasons to prefer this approach. First, this is a voluntary measure and there is a presumption that those who undertake the action intentionally designed it to achieve the chosen aim assessing costs and benefits. Second, there is a wide variety of actions to tackle the same aims. For instance, to redress the disadvantage of women in the field of engineering, a company could impart free workshops in high schools and universities for girls, as well as offering internships to women in the profession and using paid advertising to encourage women to participate, etc. All of these measures are suitable alternatives to achieve the aims, and estimating all the detrimental effects on others is a complicated and excessive burden. The third and more important reason is that unlike other applications of the proportionality test, in this case we are not looking for the most minimalist alternative. If the same company decides to reserve a quota in their training programmes for women applicants, or even give them preferential treatment in recruitment, a judge could not argue that there is a less intense positive action to be taken. The stronger the measure, the more effect it has in tackling disadvantage. The issue is therefore not in the necessity step but in the proportionality one.

The last stage of the proportionality test requires a balancing exercise of all the relevant factors. The factors at stake will depend on the particular design of the measure, but at least it must include the following: (1) the degree and seriousness of the disadvantage or low participation, or the exceptionality of the needs of the targeted group; (2) the intensity of the action, which is measured by the unfavourable effects on other persons; and (3) the duration of the action. The outcome of this strict proportionality test will determine the lawfulness of the measure. If the burden on other persons is unbearable, or greater than the obtained benefits, then this is a disproportionate positive action. This particular step of the proportionality test has at least two relevant issues: the added nuances of the concept of merit, and the concept of disadvantage and its role in the justification of positive action.

\section{The Role of Merit in the Proportionality Test}

Section 159 of the Equality Act allows giving preferential treatment to members of protected groups in connection with recruitment and promotion. This measure may have the aims of minimising disadvantage or increasing participation in a particular activity. In these cases, the proportionality principle is also the test to determine if the measure is lawful. However, there are additional requirements that demand a complex analysis. In the first place, there is a blanket prohibition on having a policy of treating persons who share a protected characteristic more 


\section{UK Anti-Discrimination Law}

favourably in relation to recruitment or promotion. ${ }^{118}$ What this provision is forbidding is the practice of automatically treating members of a protected group more favourably than those who do not share the characteristic. Each case must be assessed individually on its merits. ${ }^{119}$ As it has been explained before, this precaution is consistent with the limitations imposed by the ECJ on positive action.

Second, the candidates for recruitment or promotion must be equally qualified. ${ }^{120}$ This is not only a concern about academic qualifications but 'rather a judgement based on the criteria the employer uses to establish who is best for the job which could include matters such as suitability, competence and professional performance.' 121 This suggests that employers should have a set of criteria against which applicants will be assessed; that is, a profile that fits the specific job or position offered. Only when two candidates are equally qualified with respect to this assessment, the protected characteristic can be the deciding factor working as a tie-break criterion. ${ }^{122}$ In any case, employers must also be cautious not to indirectly discriminate when choosing the profile. For instance, requiring that employees should work under shift patterns might disproportionally affect women who are more likely to be responsible for childcare. ${ }^{123}$

The procedural requirements that both the ECJ case-law and the Equality Act provisions impose on positive action for recruitment and promotion are an attempt to reduce its effect on the cognate group. As explained earlier, the relative disadvantage condition in antidiscrimination law supposes that the protected characteristics allow us to identify groups with a significant advantage gap between them. The inclusion of equal merit in the proportionality test and the prohibition of automatic preferences prevent positive action from harming members of the advantaged group. For example, in the recent case of Furlong, ${ }^{124}$ a white heterosexual male without a disability claimed to suffer direct discrimination in a recruitment process for Police Officers. He argued that he was better qualified than other candidates, but due to a positive action scheme, Cheshire Constabulary unlawfully treated applicants with protected characteristics more favourably than he was treated. The EU cases examined in this essay are also examples of the effects on the cognate group, because the claimants are men

\footnotetext{
${ }^{118}$ Equality Act 2010, s 159 (4) (b).

${ }^{119}$ Explanatory Notes to the Equality Act 2010, para 518.

${ }^{120}$ Equality Act 2010, s 159 (4) (a).

${ }^{121}$ Explanatory Notes to the Equality Act 2010, para 518.

${ }^{122}$ Davies and Robison (n 4) 90.

${ }^{123}$ Government Equalities Office, 'Guidance. Employers: Quick Start Guide to Positive Action in Recruitment and Promotion' 22 June 2011, 6.

${ }^{124}$ Furlong $v$ Chief Constable of Cheshire [2019] 2 WLUK 725.
} 
arguing against actions that favoured women. The role of merit is to reduce the burden on advantaged persons who cannot be benefited by positive action. Therefore, this factor works in the third step of the proportionality test: proportionality in the narrower sense.

The role of merit in the justification of positive action starts from the assumption that it is possible to identify, measure, compare and rank individuals using neutral criteria. However, most of the standards we use to evaluate people have a normative and cultural content. ${ }^{125}$ The definition of merit is not value-neutral, and it may disguise stereotypes and assumptions about certain groups. ${ }^{126}$ For example, a male-centred definition of merit can replicate masculine norms that reinforce sexism in the appointment of women for senior positions. ${ }^{127}$ An alternative to favour disadvantaged groups is to consider the re-definition of merit itself as a form of positive action. Group membership may become a relevant qualification that makes someone more suitable for a particular job. ${ }^{128}$ After all, merit is not only an individualistic evaluation but also a measure of individual contribution in a team. If diversity is considered as a strength, individual identity becomes a legitimate qualification. ${ }^{129}$

For some authors, the tie-break criterion is not a positive action but rather a change in the definition of merit which includes identity, ability and personal effort. ${ }^{130}$ This view reinforces the idea that the kind of measures allowed in recruitment and promotion under UK and EU law are a watered version of positive action. Besides being a voluntary initiative, the equal merit and the strict proportionality requirement turn the preferential treatment into a soft preference at the final stages of an application process. In Furlong, the only case examining the application of Section 159, the tribunal considered that a process that selects on merits in the early stages but after the interviews stage considers all applicants as equally qualified constitutes a forbidden policy of preferential treatment. ${ }^{131}$ This case highlights that the equal merit requirement demands a complex application process allowing an objective assessment of each individual candidate. The scope for lawful positive action exists only after this assessment and can be held as justifiable if actors can thoroughly demonstrate an unbiased application process.

\footnotetext{
125 Young (n 20).

${ }^{126}$ Nick Johns and others, 'When Is Positive Action Not Positive Action? Exploring the Conceptual Meaning and Implications of the Tie-Break Criterion in the UK Equality Act 2010' (2014) 33 Equality, Diversity and Inclusion: An International Journal 97, 107.

${ }^{127}$ Simonetta Manfredi, 'Increasing Gender Diversity in Senior Roles in HE: Who Is Afraid of Positive Action?' (2017) 7 Administrative Sciences 1, 7.

${ }^{128}$ McCrudden, 'Rethinking Positive Action' (n 47) 225.

${ }^{129}$ Khaitan (n 3) 226-227.

130 Johns and others (n 126).

${ }^{131}$ Furlong (n 124), para 119.
} 


\section{'Not as Bad as...' The Concept of Disadvantage in the Justification of Positive Action under}

\section{UK Anti-Discrimination Law}

The ideal behind this state of affairs is meritocracy, where success and advancement depend exclusively on individual achievement. It is unfair to be blind to merit, but it is correct to be blind to serious disadvantage. This view has at least two important critiques. First, the ideology of meritocracy ignores and legitimises systemic inequalities. ${ }^{132}$ Second, empirical evidence suggests that strong distributive measures such as gender quotas in fact raise competence. For example, a study of the impact of gender quotas in political elections in Sweden concluded that they had 'an immediate effect on male leaders by triggering a wave of resignations of mediocre leaders.' 133

\section{The Role of Disadvantage in the Proportionality Test}

Disadvantage plays several roles in positive action. First, it is disadvantage which triggers the application of these measures. This is a group disadvantage because it must be connected with a protected characteristic. It is also serious because it requires special actions to overcome it, or because it manifests itself in under-representation or different needs that are not met under normal circumstances. While in claims of direct and indirect discrimination the protected characteristics seem neutral in the sense that it protects advantaged and disadvantaged persons, in positive action the connection with disadvantage is clearer. Anti-discrimination law reserves positive action only for the disadvantaged group who share a protected characteristic. Therefore, it is also a relative disadvantage.

The concept of disadvantage also plays an important role in the justification of positive action. In the first step of the proportionality test (suitability), the particular disadvantage is the measure against which the positive action will be assessed. In the second step (necessity), due to the deferential test that I proposed, the action should redress the particular disadvantage in the greatest possible way. It is in the third step where disadvantage plays a pivotal role weighing against the detrimental effects on other persons. On this balance, the more serious the disadvantage, the more proportionate the measure is.

The concept, measure, and assessment of disadvantage strongly depends on the positive action itself and the context where it is applied. The proportionality test is a flexible device that should adapt to the specific circumstances and should also be deferential with the organisations engaging with positive action. In this sense, the relevant disadvantage for positive action is the one targeted by the measure within the scope of the organisation's activity. At the same time,

\footnotetext{
132 Jo Littler, Against Meritocracy: Culture, Power and Myths of Mobility (Routledge 2017) 3.

${ }^{133}$ Timothy Besley and others, 'Gender Quotas and the Crisis of the Mediocre Man: Theory and Evidence from Sweden’ (2017) 107 American Economic Review 2204, 2241.
} 


\section{UCL Journal of Law and Jurisprudence}

organisations are free to redress the particular disadvantage that is relevant and compatible with their objectives. These are also important factors to weigh in the proportionality test. For instance, in Lommers, the ECJ held that in the application of positive action, employers' duties regarding equal treatment only reach their own employees. They are not required to consider other persons not belonging to their staff. ${ }^{134}$

As we have seen in EU cases, those who are negatively affected by positive action are usually members of a cognate group. Their interests compete with the interests of those benefited by the measure, but they do not have a right to be considered. As I previously explained, the proportionality test to assess positive action does not involve a conflict of rights but rather a balancing of interests. In non-recruitment contexts, the members of advantaged groups do not have a right nor even a legitimate expectation against private actors. ${ }^{135}$ The argument that tilts the balance is that by the application of positive action they suffer 'collateral discrimination'. With this concept, Khaitan explains how anti-discrimination law protects the dominant advantaged group in order to avoid damaging societal consequences. ${ }^{136}$ It may seem an oxymoron that provisions aiming to protect the disadvantaged and bridge the advantage gap between groups must also protect those who are advantaged and even privileged. However, there are also political reasons to extend the protection of anti-discrimination law to majority groups. An asymmetrical anti-discrimination duty that does not protect them will be seen as implying that their interests do not count. This will likely produce retaliation, often targeted against the protected group. ${ }^{137}$

Passing the proportionality test means that the action in question is lawful, and therefore, it is not a discriminatory act. The collateral effect on the cognate group must be less than the effect of the measure in redressing disadvantage. It is likely that because it is a relative group disadvantage, the benefits on the members of the disadvantaged group would be greater than the detriments on the cognate group. In any case, the evidence to support the justification of the measure should focus on the seriousness of the disadvantage and the suitability of the action to overcome it.

An overlooked aspect of the proportionality test is the effect on persons who are not members of the cognate group. In simple terms, a positive action that targets a disadvantaged group is tackling that particular disadvantage and not addressing others which may be more

\footnotetext{
${ }^{134}$ Lommers (n 92), para 49.

${ }^{135}$ Khaitan (n 3) 228.

136 ibid 172.

137 ibid 178.
} 


\section{UK Anti-Discrimination Law}

serious or pressing. It could be argued that because these measures are voluntary and usually undertaken by private bodies, there is not a right to be benefited from positive action. However, members of groups that share a different protected characteristic would claim that they are being discriminated against. There is a recent case that highlights this issue clearly.

In $R v$ Hackney, the claimant was a single mother of four children living in a temporary housing in Hackney. ${ }^{138}$ Under the housing allocation scheme, she was given the highest priority. However, the Borough was unable to give her a suitable home. Meanwhile, a charitable organisation (AIHA) owned several properties with the required characteristics, but they give preference to members of the Orthodox Jewish Community. The claimant alleged being discriminated against because the Orthodox Jewish Community does not suffer any relevant disadvantage that is not also shared by all the applicants for social housing in Hackney. Moreover, the allocation arrangements are disproportionate because it is a blanket policy that totally excludes non-Orthodox Jews. ${ }^{139}$ AIHA alleged that their acts were lawful under the regulation of positive action.

The Court first established that Section 158 requires correlation and not causation between the protected characteristic and disadvantage. To assess disadvantage, the Court took into account several elements. They held that there was sufficient evidence of the particular disadvantage suffered by Orthodox Jews in Hackney. First, the increase of anti-Semitism means that members of that community are more likely to be victims of crime and violence. Second, they have different needs in relation to housing because they have substantially larger families. ${ }^{140}$ Considering proportionality, the Court followed the three-stage test but focusing on the overall proportionality of the measure. They assessed the following factors: (1) the freedom of the organisation to prioritise one group over another according to their charitable objectives; (2) the compelling needs and disadvantages of the Orthodox Jewish Community; (3) the scarcity of social housing in Hackney; (4) the disadvantage of non-member individuals who may have priority for such accommodation. ${ }^{141}$ The Court held that under these conditions addressing the disadvantages and needs of the Orthodox Jewish Community outweighs the disadvantage of non-members. This case shows how the concept of disadvantage is a pivotal element of positive action, and also how its measurement is required. Moreover, this case

\footnotetext{
${ }^{138} R$ (on the application of Z) $v$ Hackney LBC [2019] EWHC 139 (Divisional Court).

139 ibid [59]-[62].

140 ibid [63]-[71].

${ }^{141}$ ibid [74]-[77].
} 


\section{UCL Journal of Law and Jurisprudence}

emphasises the difficulties of justifying a positive action that benefits a disadvantaged group but at the same time prevents other disadvantaged groups from enjoying the same benefits and opportunities.

Recently, the judgment of this case was upheld by the Court of Appeal. Lord Lewison first challenged the idea that AIHA housing allocation scheme should be examined as a positive action. His opinion is that Section 193, which regulates charities activities requires proportionate means of achieving a legitimate aim, and does not require a proportionality assessment as the one established under Section 158. ${ }^{142}$ Nevertheless, he held that weighing the following factors the allocation policy was proportionate: (1) the disadvantage to nonmembers of the Orthodox Jewish Community was $1 \%$ of the potentially available units in Hackney; (2) the needs of the community are many and compelling; (3) the allocation of properties to non-members will undermine AIHA's charitable objectives. ${ }^{143}$

\section{A different concept of disadvantage}

In positive action the relevant disadvantage is a serious group disadvantage, in the sense that it is connected with group membership. There is also an element of relative disadvantage, especially when the intensity of the measure only affects the cognate group. However, some positive actions, especially those which entail the distribution of scarce resources may also affect other disadvantaged persons. The key issue is that these other persons do not share the protected characteristic that triggers the positive action, but they are nevertheless disadvantaged. They may suffer absolute disadvantage and are more likely to be members of groups that share other protected characteristics.

As $R v$ Hackney shows, the concept of disadvantage used for the justification of positive action is slightly different from the one required in discrimination claims. A serious, group and relative disadvantage is not sufficient to outweigh the disadvantage suffered by other groups that also share a protected characteristic. In the proportionality test, especially in the stage of strict proportionality, a glimpse of absolute disadvantage is also needed; that is, individual disadvantage not necessarily connected with group membership, such as poverty or deprived socio-economic conditions. In $R v$ Hackney, the evidence supporting the disadvantage and special needs of the Orthodox Jewish Community was not only relevant to demonstrate relative disadvantage. While the charitable organisation's freedom was an important factor to justify the measure, what truly tipped the balance were the special needs and serious disadvantage

\footnotetext{
${ }^{142} R$ (on the application of Z) v Hackney [2019] EWCA Civ 1099 (Court of Appeal) [34].

143 ibid [87].
} 


\section{UK Anti-Discrimination Law}

suffered by the members of that community in correlation with their membership. The evidence to prove this was not only focused on the relative advantage gap between members and nonmembers of the community. It was also essential to demonstrate that this community experiences a more serious disadvantage than other disadvantaged groups with the same need of housing.

I argue that the relevant concept of disadvantage in the justification of positive action includes the assessment of absolute disadvantage, in the sense that it is not enough to prove relative disadvantage. In some cases, the proportionality test also requires evidence to show how a particular disadvantaged group deserves more assistance than other disadvantaged groups. Following the capabilities approach, measuring disadvantage is not an easy task, and it entails a multi-dimensional assessment. A comparison between disadvantaged groups should include the development level of each basic capability, the clustering of disadvantages and the probability of overcoming them with or without assistance. An option to avoid affecting other disadvantaged groups is to reserve intense distributive positive action to the most disadvantaged in society. Positive actions are group-oriented measures, but this is compatible with the prioritisation of those most in need within a group. ${ }^{144}$ India has vast experience with intra-group prioritisation in positive action. The Indian Supreme Court developed the 'creamy layer' test to ensure that the benefits of positive action would genuinely flow to the most disadvantaged. ${ }^{145}$ However, this approach has the risk of overlooking non-economic aspects that the capabilities approach does endorse. For example, a Dalit person may be economically well-off, but if she is excluded because of her cast membership she will be unable to develop the capability of affiliation, because she is not treated as a dignified being. ${ }^{146}$

The absolute element of the concept of disadvantage in positive action also opens an opportunity for intersectionality. ${ }^{147}$ As I argued before, in unequal societies disadvantages cluster and it is easy to identify who are the worst-off by knowing their group membership. The disadvantage suffered by a group who shares a protected characteristic is likely to be increased by the intersection of other protected characteristics. This approach permits

\footnotetext{
${ }^{144}$ Khaitan (n 3) 223.

145 Priya Sridharan, 'Representations of Disadvantage: Evolving Definitions of Disadvantage in India's Reservation Policy and United States’ Affirmative Action Policy’ (1999) 6 Asian Law Journal 99, 116.

${ }^{146}$ Nussbaum, Women and Human Development: The Capabilities Approach (n 6) 79.

${ }^{147}$ Kimberly Crenshaw, 'Demarginalizing the Intersection of Race and Sex: A Black Feminist Critique of Antidiscrimination Doctrine, Feminist Theory and Antiracist Politics' (1989) 1 University of Chicago Legal Forum 139.
} 


\section{UCL Journal of Law and Jurisprudence}

bypassing the restraints of discrimination claims that often seem 'captured by categories' ${ }^{148}$ Intersectional disadvantage could be a relevant factor to be assessed in the proportionality test of positive action. For example, it could be argued that women from an ethnic minority are more disadvantaged than White women, and therefore an action to tackle their disadvantage can be more intense. It also helps to balance the disadvantage suffered by groups who share different protected characteristics. One of them can be more disadvantaged if we take intersectionality into account.

The requirement of absolute disadvantage in the justification of positive action matches the flexibility and concrete approach of the proportionality test. Depending on the type of organisation, the scope of its activity and the positive action undertaken, the assessment of absolute disadvantage will vary. Organisations should try to address the most disadvantaged group regarding a certain underrepresentation or the existence of special needs. For instance, if the goal is to increase the participation of women in a particular field, a proportionate positive action should focus on those women who are more disadvantaged. In the UK, this assessment would probably imply race as a protected characteristic rather than marital status because the national data supports that ethnic minorities are the most disadvantaged within British society. ${ }^{149}$ However, in some cases there is no scope for an element of absolute disadvantage at all. If a company is willing to engage with positive action to increase the number of women in high ranked positions, it is very unlikely that in doing so, they could redress absolute disadvantage. Highly educated women are also the more advantaged among them. In this sense, not all positive action requires the relevant factor of absolute disadvantage in the proportionality test.

Finally, the fact that the justification of some positive actions requires an absolute element of disadvantage does not lead to consider that these measures are the most suitable tools to address absolute disadvantage. On the contrary, basic human needs such as health care, housing and education should be guaranteed in a basic threshold for all persons independently from their group membership. Such needs are essential to the development of basic human capabilities and should not depend on individual litigation or voluntary measures. Acknowledging the potential of positive action and their de-clustering power is compatible with standing up for welfare systems. Nevertheless, a clear and distinctive concept of disadvantage for positive action allows us to improve the design and judicial defence of these

\footnotetext{
${ }^{148}$ Sandra Fredman, 'Equality: A New Generation?' (2001) 30 Industrial Law Journal 145, 157.

${ }^{149}$ Equality and Human Rights Commission (n 16).
} 
'Not as Bad as...' The Concept of Disadvantage in the Justification of Positive Action under UK Anti-Discrimination Law

measures. Proportional and disadvantage-focus positive action is the sharpest tool of antidiscrimination law to redress inequality.

\section{E. CONCLUSION}

The concept of disadvantage is multi-dimensional and should encompass the development of several aspects of life as the ones included in the basic human capabilities listed by Nussbaum. In anti-discrimination law, such as the UK Equality Act, the relevant concept of disadvantage meets three conditions. It is serious, connected with group membership, and relative in the sense that it shows an advantage gap between groups classified under the same protected characteristic. The aim of anti-discrimination law is to break the connection between group membership and disadvantage.

Positive action is the ultimate tool to de-cluster disadvantages. The relevant concept of disadvantage in the justification of positive action is slightly different from the one required to support discrimination claims. This disadvantage is also a group, relative and serious disadvantage. However, sometimes it requires an additional element to surpass the proportionality test and avoid discriminatory effects on other disadvantaged groups; it is necessary to prove an absolute disadvantage. The use of positive action in the allocation of scarce goods and opportunities should redress absolute disadvantage rather than only a relative one.

The proportionality test is a flexible device that includes the assessment of several elements. This test should be deferential with the actors undertaking positive action. The seriousness of the disadvantage and the suitability of the measure to redress it should be the main factor to be considered. The added element of absolute disadvantage opens the door to prioritisation within disadvantaged groups and the inclusion of an intersectional approach. Nevertheless, while acknowledging the potential of positive action, basic goods and services should be generally distributed disregarding group membership. Anti-discrimination provisions and positive action do not replace welfare systems and the necessary public policy to overcome inequality. 